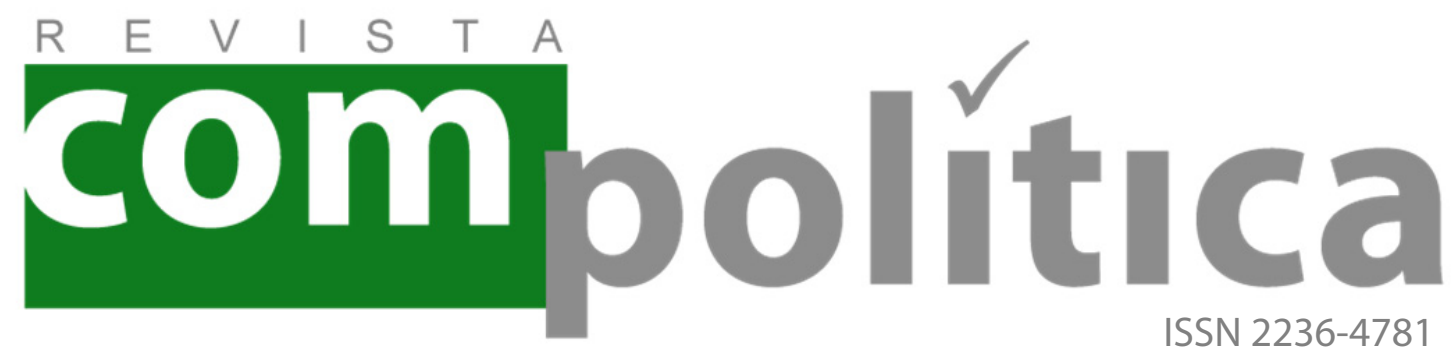

GOMES, Wilson

Professor Titutar da Universidade Federal da Bahia. Doutor em Filosofia pela Universitas a Scte. Thomae, Roma.

<wilsonsg@terra.com.br>

\title{
Entrevistas com candidatos a presidente transmitidas "ao vivo" em telejornais: o modelo teórico-metodológico da mediação jornalística
}

\section{RESUMO}

Em anos eleitorais, as entrevistas com candidatos, exibidas "sem edição nem corte", geralmente transmitidas diretamente das bancadas dos telejornais de rede e conduzidas pelos apresentadores mais importantes do telejornalismo brasileiro, transformaram-se em elementos fundamentais da representação jornalística das campanhas políticas no Brasil. A impossibilidade de edição é em geral vendida como garantia de uma autorrepresentação genuína e autêntica da política diretamente aos eleitores. Este artigo é uma sustentação argumentativa de que, na verdade, antes que um meio de apresentação da política na televisão, a entrevista eleitoral não editada é uma arena em que a instituição do jornalismo, sem poder contar com as vantagens de edição usualmente à sua disposição na cobertura política quotidiana, tenta por meios retóricos e recursos discursivos manter o seu controle sobre a fala política.

Palavras-chave: Entrevistas eleitorais; campanhas presidenciais; jornalismo político.

\section{ABSTRACT}

In election years, television interviews with presidential candidates, broadcast live, i.e. without the use of editing, have become an important genre of journalistic representation in Brazilian political campaigns. These interviews are conducted in network studios by well-known Brazilian news anchors. The fact that these interviews are transmitted directly to the electorate in an unedited form is generally offered as a guarantee of a genuine, authentic portrayal of the candidates themselves. The present work proposes that live network candidate interviews, rather than a means of political presentation on television, are actually an arena in which the institution of journalism attempts to use rhetorical and argumentative means to control the candidates' discourse without relying on the traditional advantages conferred in daily news coverage.

Keywords: live candidate interviews; presidential campaigns; political journalism. 


\section{Entrevistas com candidatos a presidente transmitidas "ao vivo" em telejornais: o modelo teórico-metodológico da mediação jornalística}

\section{[Interviews with candidates for president transmitted "live" on TV news: the theoretical-methodological model of journalistic mediation]}

GOMES, Wilson

$\mathrm{N}$

o jornalismo, a entrevista geralmente é uma forma de coleta de informações. Inclusive sobre a política. Como espécie do gênero, o jornalismo televisivo tem nas entrevistas uma das suas matérias primas, mas as trata previamente e as encaixa no telejornal na forma de vídeos editados. A entrevista política "ao vivo" - no rádio, na TV ou nos portais de notícia - é uma exceção ao procedimento do tratamento e da edição prévias, uma vez que insere no noticiário um ato conversacional em que o tempo da realização e o tempo da transmissão são simultâneos. Supõe-se que, uma vez excluída a edição prévia, não haveria o controle e o tratamento jornalístico sobre o discurso do entrevistado, de forma que a conversação que se desenrola na entrevista direta não apenas seria imediata, mas seria também sem mediação - seria a presença e a voz da política não controlada, não filtrada, portanto, autêntica, oferecida diretamente ao público. Os ganhos de autenticidade superariam as perdas produzidas pelo risco de erro e de descontrole típicos de qualquer coisa que seja exibida no noticiário sem corte ou edição ${ }^{1}$.

No Brasil, tornaram-se comuns em anos eleitorais as entrevistas a candidatos transmitidas diretamente das bancadas dos telejornais,

\footnotetext{
${ }^{1}$ Ao lado da entrevista "ao vivo" se coloca aquele tipo de entrevista gravada que não sofre processo de "edição ou corte". Ela atenderia a todos os requisitos do "ao vivo", exceto pelo fato de que não há simultaneidade entre realização e exibição. Nas eleições de 2010, tivemos exemplos dessa ocorrência. Primeiro, houve as entrevistas de Plínio de Arruda Sampaio, que não foram geradas na bancada, mas por repórteres designados, nem foram exibidas simultaneamente à produção. Segundo, tivemos as entrevistas de Dilma Rousseff e José Serra ao Bom Dia Brasil gravadas na noite anterior, na bancada do telejornal. Nos dois exemplos, a emissora assegurou não ter havido edição prévia à exibição da entrevista.
} 
dos noticiários de rádio, dos programas de entrevistas do rádio e da televisão e, ultimamente, dos estúdios audiovisuais dos portais de notícias. Durante as eleições para presidente da República, as entrevistas ocupam um lugar central, concorrendo em audiência e importância com os já consolidados debates eleitorais na televisão. $\mathrm{Na}$ última eleição presidencial, em 2010, não houve telejornais importantes de rede que não tentassem a sua entrevista "ao vivo", ao menos com os três principais candidatos. A Rede Globo, por exemplo, reservou 12 minutos do Jornal Nacional, no $1^{\circ}$ e no $2^{\circ}$ turnos, para entrevistas diretamente da sua bancada para cada um dos três principais candidatos, além de 20 minutos do Jornal da Globo e do Bom Dia Brasil no $1^{\circ}$ turno. E a candidata eleita esteve na bancada do Jornal Nacional durante uma edição posterior à proclamação do resultado eleitoral. A entrevista eleitoral direta, encaixada no noticiário de televisão, tornou-se, no Brasil, uma alternativa de sucesso ao formato americano do debate presidencial na TV.

Numa entrevista política não editada, supõe-se que o objeto e a razão de ser de tudo sejam o candidato e o interesse público. A entrevista tem como propósito proporcionar a satisfação do interesse público e facilitar a autorrepresentação do candidato entrevistado. Esta suposição, entretanto, pode se revelar simples demais. Sustenta-se neste trabalho a hipótese de que uma entrevista eleitoral não editada é antes uma arena argumentativa do que um espaço de exibição da política. Na verdade, em entrevistas não editadas se confrontam as instituições da política e do jornalismo. Os entrevistadores não são meros mestres de cerimônia, mas principalmente atores numa arena argumentativa que travam com o ator político uma tensa negociação sobre o conteúdo e a forma das suas falas.

\section{Um modelo teórico para a abordagem das entrevistas eleitorais não editadas: a mediação jornalística}

Num artigo originalmente publicado em 1992, Soundbite news: television coverage of elections, 1968-1988, Daniel C. Hallin defendeu que a natureza e o estilo da cobertura política do telejornalismo haviam "mudado dramaticamente" pari passu com o aumento da centralidade da TV nas campanhas presidenciais. Hallin diz que, apesar de ser uma mudança complexa, um simples indicador - a extensão das sonoras dos políticos presentes nos telejornais forneceria um meio apropriado de entender em que sentido as transformações estão ocorrendo (HALLIN, 1994). Sonoras, ou sound bites, são os segmentos de fala contínua de um entrevistado inseridos em uma matéria na televisão ou no rádio. A pesquisa empírica apresentada no artigo de Hallin demonstra como as sonoras dos atores políticos presentes nos telejornais americanos 
diminuíram drasticamente durante o vintênio que vai de 1968 a $1988^{2}$, justamente aquele em que o telejornalismo se tornou um componente central da representação pública da política.

Mais importante do que ter documentado a mudança por meio desse indicador, será a conclusão de que o encurtamento da sonora dos políticos reflete transformações relacionadas à estruturação das matérias no jornalismo de televisão e ao papel que o jornalismo desempenha nisso. As matérias de política do noticiário de TV são muito mais uma composição do que uma justaposição das falas dos jornalistas e dos políticos, como costumava ser; com isso, o jornalismo ganha um papel bem mais ativo, in putting it together, na composição da peça final que irá ao ar. A esta maior presença e intervenção do jornalismo no conjunto do material que constitui a cobertura política, Hallin vai chamar de mediação.

A notícia de política é em geral decorrente da coleta de fatos, depoimentos e declarações por parte do jornalismo. Em 20 anos ocorreu uma forte mudança de atitude do jornalismo de TV, que num primeiro momento entende-se como instrumento para coleta da fala dos entrevistados e meio para que ela seja "reproduzida e transmitida ao público", enquanto numa segunda fase passou a empregá-la simplesmente como matéria prima que só depois de tratada terá uso nos telejornais. A reportagem de TV correspondente à primeira atitude está a serviço da apresentação da fala de autoridades e candidatos; a matéria que corresponde à segunda atitude é dominada pela fala de repórteres e apresentadores. Antes, é resultado de um trabalho de intervenção que se situa após a coleta da fala política por meio de entrevistas, no qual a matéria prima resultante de uma entrevista - áudio e vídeo - é desmontada, desencaixada, combinada com falas gravadas em outras entrevistas, cortada em fatias menores, ajustada a materiais de natureza visual, reencaixada na fala produzida por repórteres e âncoras para dar sentido, ritmo e narrativa ao conjunto que formará a matéria.

Hallin não menciona, mas a fala política na entrevista pode sofrer vários níveis de intervenção jornalística. $\mathrm{Na}$ fase de produção da matéria já se estabelece a decisão sobre os ângulos de abordagem, a seleção dos assuntos e das perguntas, além da seleção dos entrevistados. Realizada a entrevista, antes de a matéria chegar à mão dos editores, o repórter já a terá convertido numa narrativa (no jargão brasileiro, na gravação do off) usando um ângulo de abordagem (ou gancho), que funcionará como base para a decisão posterior sobre que parte do material gravado será aproveitado ou

\footnotetext{
2 "A extensão da sonora média encurtou - de mais de 40 segundos em 1968 a menos de 10 segundos nos anos 1980 (...)” (HALLIN, 1994 : 131). No Brasil, numa pesquisa que realizei em 2009, a sonora média do Jornal Nacional era de $12,9 \mathrm{~s}$ (GOMES, 2009: 195).
} 
descartado e sobre a necessidade ou não de combiná-lo com material de arquivo. Depois da edição, a fala do jornalismo (em geral, dividida entre repórteres e apresentadores) se apresenta em sucessivas camadas discursivas (chamada, cabeça, passagem, fechamento, notas...) que organizam o sentido da matéria e dominam as falas dos entrevistados, determinam seu lugar, extensão, sentido e interação. Isso se faz para produzir uma narrativa audiovisual coerente, mas implica em sustentar um ponto de vista, um argumento acerca de um fato, evento ou realidade política. Houvesse, como no passado, uma autocontenção nas palavras fornecidas na entrevista, o centro da matéria seria o que o próprio político diz; como não há, o que realmente importa agora é o que o jornalismo diz sobre os assuntos de política.

Uma reportagem de TV precisa ter a unidade de uma linha cronológica e narrativa (story-line) (HALLIN, 1994: 138) e precisa de um desfecho. Hallin usará expressões metafóricas (wrapping up, packaging, sum up, closing lines) para designar esta intervenção do jornalismo sobre o texto dos políticos, todas relacionadas à ideia de encerramento, fechamento, de remate ${ }^{3}$. 0 jornalismo, então, não apenas monta uma história, mas lhe dá coerência e sentindo de conjunto, rematando-a, dando-lhe um desfecho - assegurando-se, afinal, a última palavra. Remate aqui tem o sentido de uma operação destinada a tornar a narrativa completa, acabada - não é simplesmente a obrigação estética de produzir, no jargão, um elegante "off de encerramento", mas se trata de dizer o que nós devemos considerar como o sentido apropriado e definitivo do que ouvimos e vimos na matéria ${ }^{4}$.

\section{Mediação como controle}

Do argumento de Hallin, gostaria de destacar algumas intuições a serem mantidas e exploradas. Primeiro, o foco adotado por ele é menos comum do que parece à primeira vista. Em vez de produzir generalizações sobre o modo como a televisão exerce o efeito X ou $\mathrm{Y}$

\footnotetext{
3 “Este remate [packaging] significa que a matéria jornalística moderna é muito mais centrada no jornalista [journalist-centered] do que o seu formato anterior: o jornalista, não o candidato ou outra categoria de 'fazedores de notícia' (...), é o comunicador primário" (HALLIN, 1994: 138). Todas as traduções neste artigo são de responsabilidade do autor.

${ }^{4}$ Outros autores desenvolveram esta linha de pesquisa iniciada por Hallin, investigando outras dimensões da mediação jornalística no noticiário de TV. Alguns produziram interessantes desdobramentos investigando o equivalente visual das sonoras, chamados de "image bites" (BARNHURST; STEELE, 1996; GRABE e BUCY 2009; BUCY; GRABE, 2007), enquanto outros adotaram a perspectiva de que há diferentes culturas jornalísticas locais envolvidas em diferentes modos de produção de sonoras e image bites (ESSER, 2008; BARNHURST, K.; MUTZ, 1997).
} 
sobre a política, concentra-se no estudo das características estruturais do jornalismo de TV. Considero que a pesquisa sobre o noticiário político na TV em particular ganha em concretude e em capacidade empírica se o foco permanecer na materialidade por meio do qual o telejornal existe: a reportagem. Mas acho que a agenda pode ser alargada para se estudar não simplesmente o noticiário político, mas a integralidade da presença da política no telejornalismo, o que inclui também a entrevista política direta da bancada do telejornal.

Segundo, a ideia da mediação. Embora seja uma expressão excessivamente polissêmica, acredito poder extrair e desenvolver uma intuição muito fecunda incluída nela: na materialidade do telejornal há uma tensão entre a instituição do jornalismo e a instância política; esta tensão tem produzido um crescente controle, por parte do jornalismo, da voz dos atores políticos no noticiário.

Não é preciso restringir-se, como Hallin, a inferências sobre a natureza e o estilo da cobertura jornalística das campanhas presidenciais. Como ele finda por reconhecer, "a mudança na cobertura da campanha é parte de uma mudança mais ampla no jornalismo" (HALLIN 1994: 139). Neste trabalho, sustento a hipótese de que há mediação ou controle do jornalista em qualquer ocasião em que o jornalismo é acionado para intermediar o discurso político ou para dar-lhe formato adequado para a programação jornalística televisiva.

Este trabalho se apoia num estudo das entrevistas sem edição durante as eleições presidenciais de 2010 no Brasil, que será objeto de outro artigo, em que foram analisadas 14 entrevistas televisivas, a fim de verificar se e que tipo de controle jornalístico da imagem e da voz da política pode ser exercido em outro gênero por meio do qual o discurso político se apresenta na televisão sob a mediação do discurso jornalístico. Este artigo consiste num exame conceitual do tipo de mediação ${ }^{5}$ presente nas entrevistas transmitidas diretamente das bancadas dos telejornais ou, dito de outro mod, das formas de disputa pelo controle da voz da política pelo jornalismo nas entrevistas não editadas.

\section{A entrevista direta como arena argumentativa}

\footnotetext{
${ }^{5}$ Entendo por mediação jornalística qualquer procedimento de tratamento da voz ou discurso dos atores políticos por qualquer uma das diversas instâncias do jornalismo e que, ademais, se reflita no produto levado ao ar.
} 
$\mathrm{Na}$ entrevista direta na TV é necessário que entrevistador e entrevistado reconheçam seus papéis, comportando-se de acordo com regras implícitas. Mats Ekström (EKSTRÖM, 2001, 2012) dá alguns exemplos de convenções básicas do gênero: o jornalista é quem começa e termina falando e quem toma a iniciativa e convida o político a falar; o entrevistado deve saber que o entrevistador é quem tem o poder de estabelecer a agenda e decidir que temas a conversa deve cobrir; cabe ao entrevistado cooperar, respondendo às questões, sabendo-se que se recusar a responder também é uma resposta à questão.

O telejornal não leva a entrevista eleitoral para a sua bancada apenas para dizer que, como não filtrou o que o candidato está dizendo, o espectador tem agora uma relação direta com o que o político pensa e quer. Mais que isso, espera-se que o jornalista use a sua autoridade para: (a) fazer questões que permitam ao público obter do político toda a informação política necessária para uma decisão eleitoral qualificada; (b) impedir que o político manipule a audiência com respostas inconclusivas ou falsas, informações distorcidas sobre si ou sobre os adversários ou simplesmente produza mais propaganda. Assim, a autenticidade parece garantida ao mesmo tempo pela ausência de filtros, supressões e acréscimos que alterem a voz genuína do ator político, mas também pela presença de constrangimentos produzidos pela autoridade jornalística que está ali, presente e vigilante.

A este ponto da argumentação, deve ser claro que há um pressuposto funcionando à base dessas operações argumentativas, e que é compartilhado pelo menos pela instituição do jornalismo e pela sua audiência. Segundo tal pressuposto, a política é um poder manipulador e o jornalismo é um poder revelador ou desmascarador. É investido desta crença que o apresentador de um telejornal se apresenta em sua bancada para a entrevista direta com políticos, principalmente para as entrevistas com candidatos ${ }^{6}$.

O capital específico da instituição jornalística (autoridade, prestígio e visibilidade) está em jogo nas entrevistas diretas. Audiência e políticos atribuem autoridade jornalística apenas ao ator de quem se presume, antes de tudo, conhecimento profundo, atualizado e relevante sobre os fatos da atualidade. Credibilidade, por sua vez, não é apenas uma distinção cognitiva, mas moral: atribuímos credibilidade não apenas a quem acreditamos que conheça aquilo de que fala, mas também ao ator de quem acreditamos que não se engane nem nos engane a respeito dos fatos que nos apresenta

\footnotetext{
${ }^{6}$ Note-se que este pressuposto não precisa estar presente na entrevista com artistas e celebridades, com pessoas do universo da cultura e da ciência ou com especialistas - é uma premissa reservada para a contraposição entre jornalismo e política.
} 
(BOWEN et al., 2000; MEYER et al., 2010; NORRIS, 2002). A instituição jornalística empresta à entrevista a credibilidade que lhe é própria, pois é papel dos jornalistas garantir informação política de qualidade. Mas além de prestígio e credibilidade, jornalistas são mais ou menos importantes em virtude da visibilidade de que gozam por causa da sua dupla condição de parte tanto do universo da televisão quanto do jornalismo; a visibilidade do jornalista, valor importante para a atração de audiência, tem como subproduto o reconhecimento do público e o vínculo afetivo conseqüente. Os entrevistadores, portanto, estão em geral ungidos por prestígio, credibilidade, autoridade jornalística, celebridade e simpatia.

Exceto para os militantes e para os que são fortemente vinculados a determinada candidatura (GINER-SOROLA; CHAIKEN, 1994; GUNTHER, 1992; HUGE; GLYNN, 2010; RICHARDSON et al., 2008; VALLONE et al., 1985), o jornalista geralmente é a figura dominante durante uma entrevista eleitoral. Mesmo quando o político tem um patrimônio equivalente em alguns ou em todos os quesitos indicados acima, ainda assim haverá uma parte dos eleitores - adversários, indiferentes ou independentes - que tende à adesão emocional e cognitiva aos entrevistadores. Por fim, o público sabe e reconhece que a bancada do telejornal é o habitat próprio dos apresentadores de TV - na condição de anfitriões, são eles que mandam. Os políticos são os hóspedes a quem se recebe com cortesia, mas de quem se espera que respeitem as regras da casa, inclusive aquela que diz que o poder ali se distribui assimetricamente.

Por todas essas razões, a entrevista eleitoral necessariamente é uma competição pelo controle da argumentação e assim é considerada pelos atores das duas instituições envolvidas. O prestígio jornalístico e o êxito político estão sempre em jogo, de forma que, em condições normais, as duas partes tendem a levar muito a sério o seu papel. Eis por que o jornalismo toma providências para controlar o que os políticos dizem na entrevista.

A mediação se dá em dois níveis. O primeiro tem a ver com as atitudes adotadas pelos entrevistadores no próprio ato de perguntar. Atitudes são disposições cognitivas e emocionais. No caso, ceticismo ou crença, hostilidade ou simpatia, desconfiança ou confiança são pares de atitudes comumente empregados em entrevistas. A atitude do entrevistador, se não a determina diretamente, ao menos influencia consideravelmente o tom geral da entrevista e a atitude do entrevistador - sem mencionar a disposição da audiência. Se, como é comum, a atitude dos apresentadores for mais de ceticismo do que de credulidade, o entrevistado deve esperar que o seu tempo de fala seja reduzido, e que ele seja constantemente interrompido por correções, observações, contestações factuais. Ao adotar uma atitude em face do candidato e do que ele diz, o entrevistador estabelece, ao mesmo tempo, o estado de espírito com que o conteúdo da fala do 
candidato será recebido pela audiência e como o próprio candidato será tratado durante o resto da entrevista.

A segunda providência de controle tem a ver com os comportamentos verbais usados pelos apresentadores para manter os entrevistados na linha. Intervenções corretivas, interrupções de raciocínio, recusa dos percursos argumentativos, contestação de afirmações, reiteração do ponto de vista, mudança de assunto e insistência são exemplos de atos verbais empregados para o controle jornalístico da fala política em entrevistas não editadas.

\section{A competição argumentativa}

A competição pelo controle da argumentação se realiza por meios de estratégias argumentativas e de atos retóricos em que se envolvem jornalistas e políticos. Como estão "em casa", os jornalistas se asseguram tantas vantagens quanto possível: determinam os temas da entrevista, as questões por meio das quais os temas são tratados e que já são do conhecimento do jornalista, mas não do entrevistado, podem recusar o script e o enquadramento que o candidato escolher, às vezes no improviso, para lidar com as questões, dizem quando o candidato deve parar de argumentar, podem permanecer num argumento desvantajoso para o candidato o quanto queiram, podem comentar, recusar ou corrigir as respostas do candidato, usando o privilégio que consiste no fato de que, ao menos naquele espaço, o seu capital é maior do que o do entrevistado. O fato de haver vantagem para os entrevistadores não significa que os entrevistados não tenham poder algum frente a eles; na verdade, tentam usar estratégias para passar as suas mensagens e exploram alternativas para atingir suas metas e resistir aos avances do entrevistador.

\section{A distribuição das oportunidades de falar nas entrevistas}

O primeiro nível de competição entre jornalismo e política é uma disputa pelas chances de falar. Uma vez que as oportunidades são finitas, a assimetria na distribuição das quotas de fala é uma possibilidade constante. No noticiário político, reservam-se cotas mínimas à fala direta da política e todo o resto do tempo é usado por apresentadores e repórteres. Supostamente, numa entrevista com candidatos, principalmente no caso de candidatos à Presidência da República, quem está no centro é o político. Ele é a razão da entrevista. Há de se esperar que a entrevista seja concebida de tal forma que o político tenha tempo, tranquilidade e todas as 
oportunidades necessárias para a apresentação de si mesmo, das suas idéias, da sua compreensão dos problemas sociais, da sua agenda, das políticas que deseja sustentar. O que acontece, contudo, pode estar bem distante deste pressuposto.

Os políticos têm as suas oportunidades de fala, mas os jornalistas precisam controlá-las com as perguntas certas e as intervenções verbais que as acompanham. Para isso, usam questões e comportamentos verbais de controle da fala do entrevistado, consumindo parte do tempo da entrevista, em alguns casos, em abundância. Como o tempo de TV é um recurso escasso, quanto mais tempo consome o jornalismo e menos tempo resta para os candidatos, menores são as oportunidades que estes têm de passar a sua mensagem.

A impressão de que o jornalismo ter-se-ia tornado muito "espaçoso" nas entrevistas é confirmada pelas medidas globais de rateio da amostra estudada, medindo-se por palavras ou por tempo de fala. Embora se note a diferença de comportamento entre, por exemplo, os apresentadores do Jornal Nacional e os do Jornal da Globo, é evidente que o jornalismo consome parte considerável do espaço. A "vantagem" (tempo excedente que o entrevistado tem além do tempo do entrevistador) pode chegar a apenas $1 / 4$. 0 que cria a estranha situação em que, numa entrevista de 12 minutos, a audiência tenha que ouvir o jornalista por 4,5 minutos e o candidato tenha apenas 3 minutos a mais que este.

Tabela 1 - Divisão do número de palavras entre jornalistas e políticos

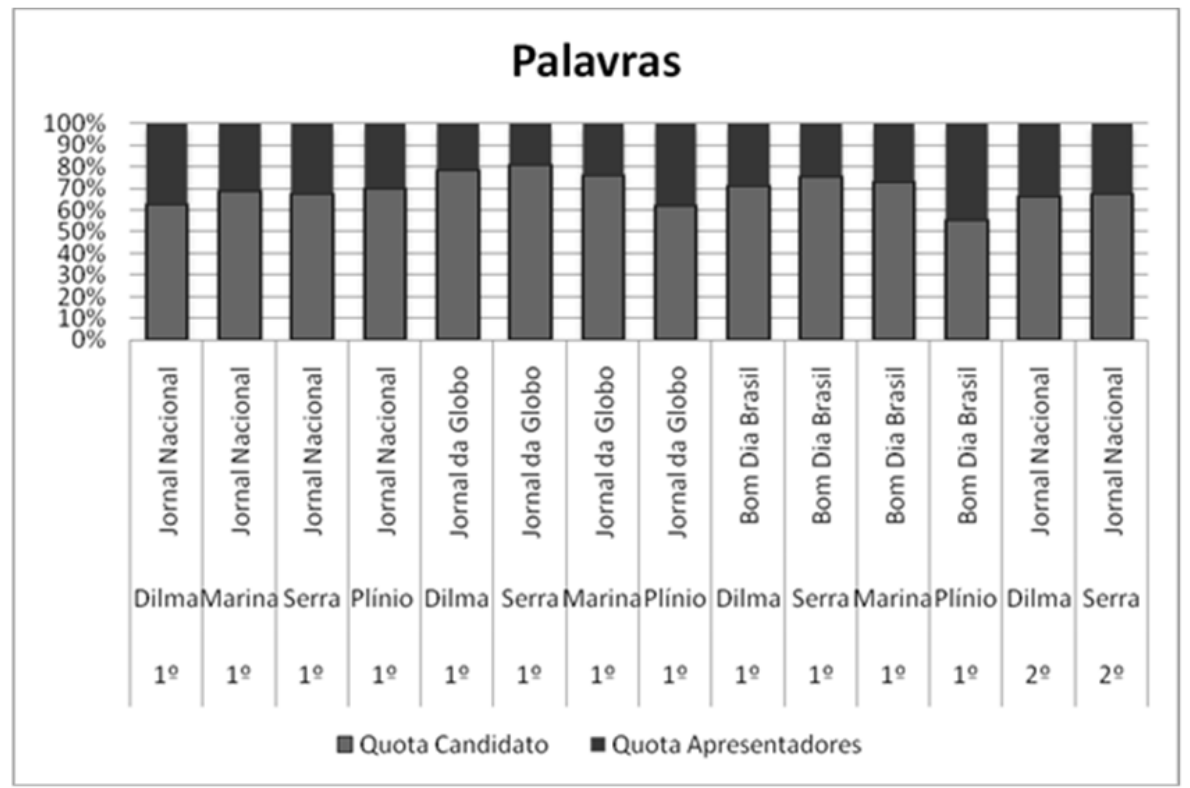

A medição do rateio da fala nas entrevistas diretas no Brasil pode ser muito variável e muito dependente do estilo de cada telejornal. Num 
jornal em que os apresentadores adotem uma posição mais hostil, como o Jornal Nacional, os âncoras consomem sempre acima de $30 \%$ do tempo e das palavras da entrevista, podendo estender a sua colonização a $40 \%$ do total, enquanto num telejornal de perfil mais cordato e uma atitude mais cooperativa, como o Jornal da Globo, os apresentadores geralmente falam menos que $20 \%$ da entrevista. Em todos os casos, porém, o jornalismo reserva para si uma porção importante das oportunidades de fala disponíveis.

\section{A competição pelo controle da argumentação}

O segundo nível de competição pode ser ainda mais importante, e tem a ver com o modo como a instituição jornalística usa a sua quota de falas para o controle da fala do político. Como a entrevista é uma atividade conversacional - o que supõe ao menos dois sujeitos negociando os seus percursos argumentativos, frames, procedimentos demonstrativos, duração e distribuição das falas e, por fim, regras de polidez -, pode-se examinar como e até que ponto uma das partes pode assumir o controle dos atos discursivos da entrevista. Diferentes comportamentos conversacionais básicos são parte da luta a) pelo predomínio dos pontos de vista, pela imagem de si que se quer transferir, pela chance de persuasão da audiência mediante o controle dos enquadramentos e das premissas adotadas; b) pela condução dos raciocínios, o que inclui desde a dimensão da elocução sem interrupção (por quanto tempo alguém pode continuar falando sem ser interrompido) até a decisão sobre quem tem a última palavra.

O jornalista de televisão é acostumado ao ritmo e às características da sonora política de 10 segundos emoldurada pela fala do jornalismo que a contextualiza, explica, estende, completa ou contesta. Na matéria típica, a fala política é "depurada" pelo jornalismo não apenas das marcas da hesitação, da incompletude, dos recomeços e autocorreções, das orações subordinadas e dos silêncios - tudo isso que entra na conta dos "ruídos" -; é reduzida, na verdade, ao cerne, na forma de sentenças gramaticalmente em ordem direta e logicamente assertivas. Mas a entrevista direta não produz uma coleção de sentenças desta natureza: os problemas da realidade são complexos, os fatos têm nuances, as posições são complicadas, as ideias precisam de distinções e paradoxos. Além disso, a imposição da improvisação, o desconhecimento prévio das questões, a atitude frequentemente desconfiada e hostil dos entrevistadores, as perguntas-armadilhas que são formuladas para colocar os candidatos em uma situação difícil, tudo isso fatalmente produz um discurso com hesitações, mudança de percurso dos raciocínios e uma atitude argumentativa que precisa de distinções, 
reposicionamento de pressupostos, alusão a outros fatos ou, no limite, o desvio das cascas de bananas lançadas pelos apresentadores.

Paradoxalmente, os jornalistas colocam os entrevistados numa situação em que eles não podem dar respostas lapidares e abreviadas, mas desejam a frase curta, direta e precisa que ao mesmo tempo constitua uma resposta honesta, sincera, sem manipulações e sem subterfúgios. Assim, como não podem editar a fala política mediante os procedimentos tradicionais do corte-encaixe-emoldura, em vista da circunstância do "vivo", tentam editá-la no curso da entrevista, por meio de constrições e constrangimentos verbais imperativos: "não foi exatamente o que perguntei, candidato", "então, me explique também o fato A e B", "gostaria de interrompê-lo para dizer que...".

Os comportamentos argumentativos empregados na competição pelo controle da argumentação são vários, mas na nossa amostra o controle da argumentação foi disputado por meio dos seguintes comportamentos conversacionais:

Quadro 1 -

\begin{tabular}{ll}
\hline Entrevistadores & Entrevistados \\
\hline Premissas embutidas & Esquiva \\
\hline Reiteração & Captatio benevolentiæ \\
Reforço & Escapada \\
\hline Perseguição & Questionamento explícito da premissa \\
Interrupção de raciocínio & \\
\hline Mudança de assunto & \\
\hline
\end{tabular}

Premissas embutidas nas perguntas. Trata-se da prática de encaixar uma premissa (tese) na pergunta formulada ao candidato. Em coerência com a pretensão desmascaradora, a premissa tende a ser desfavorável ao candidato - neste sentido, a indagação é frequentemente um cavalo de Tróia que comporta um adendo perigoso, com que o entrevistado tem que lidar. De todo modo, a premissa embutida tende a pôr o candidato no lugar em que o jornalista deseja - uma posição defensiva.

Reiteração. Se o entrevistado adotar algum comportamento de resistência ou reação à premissa, o entrevistador contra-ataca com a 
reiteração - a reafirmação, por meio de nova pergunta, da premissa inicial. Poderá fazer isso várias vezes, até que decida mudar de assunto.

Reforço. O reforço é tática auxiliar à reiteração. Trata-se de oferecer suplementação argumentativa ou factual (dados, números, informação) à premissa sustentada desde o início. Geralmente, o reforço é introduzido por meio de interrupção do entrevistado.

Perseguição ou acossamento. É um comportamento frequentemente adotado quando se trata de manter a resposta do candidato nos limites preestabelecidos pela pergunta básica e ele insiste em empreender esquivas ou fugas argumentativas. Quando os candidatos resolvem desprezar a pergunta ou a premissa posta e não reagem aos atos correcionais de reforço ou reiteração, os jornalistas adotam ondas sucessivas de reiteração e reforço até que o candidato se submeta ao script previsto na indagação de partida. William Bonner se destacou em 2010 por realizar sucessivas perseguições argumentativas aos vários candidatos.

Interrupção de raciocínio. Raciocínios são processos argumentativos. Interromper um raciocínio de alguém é impedir que ele conclua um argumento, leve a termo um pensamento, conclua a exposição de uma ideia. Numa conversa normal, as pessoas tendem a sinalizar a quem está argumentando que desejam falar em seguida e, que, portanto, o raciocínio precisa ser abreviado e concluído, em vez de "falar por cima" ou interromper a palavra e o pensamento de quem está falando. Além disso, os vários lados negociam o poder de encerrar os argumentos e raciocínios, estabelecem acordos, trocam de posição, barganham tempo e extensão do argumento. $\mathrm{Na}$ entrevista política muitas vezes os jornalistas interrompem os políticos (e os políticos, por sua vez, "falam por cima" da fala que os está interrompendo). o jornalista interrompe para inserir um dado novo, refazer a pergunta, mudar o rumo da resposta ou, simplesmente, para encerrar a argumentação - sem importar, na verdade, se para o candidato o argumento tenha ou não se completado. Trata-se de uma intervenção de autoridade e depende exclusivamente do arbítrio dos entrevistadores. Os maiores conflitos argumentativos se dão por esta razão: o candidato deseja continuar falando, o jornalismo determina que ele pare de falar. Trata-se claramente de um dispositivo de poder argumentativo: o poder de mandar encerrar uma argumentação, de estabelecer tema e duração de argumentos, de determinar quando já se falou o suficiente ou o quanto a resposta pode ser considerada adequada ou inadequada. 
Mudança de assunto. É o jornalismo quem decide que temas entrarão nas perguntas e quem se esforça para determinar os temas que estarão nas respostas, o que é uma vantagem argumentativa enorme. Mas, além disso, o jornalista determina também por quanto tempo se pode ficar num tema, quando a sua exploração é suficiente, quando um novo tema deve ser chamado.

Em face dos comportamentos de tática discursiva do jornalismo, os entrevistados desenvolveram estratégias de sobrevivência argumentativa. Mesmo em situação de considerável desvantagem, o ator político desenvolveu habilidades argumentativas importantes, para tentar evitar as armadilhas e embaraços que lhe são apresentadas pela maioria das questões.

Esquiva. São os comportamentos adotados pelos entrevistados para evitar serem levados para fora da sua zona de desconforto pelos jornalistas, sem, no entanto, partir para um confronto direto nem explicitamente evitar a questão. Consiste em responder parcialmente, em responder apenas após ter reinterpretado a premissa, em produzir leves mas consistentes alterações nos pressupostos ou no foco, em fingir não ter compreendido as dimensões mais embaraçosas da questão, em começar a responder para logo mudar para um tópico da sua zona de conforto, etc. Como não estimula o confronto direto e a recusa acintosa, é o comportamento de desvio das armadilhas com maiores chances de sucessos.

Captatio benevolentice. Trata-se de procedimento retórico e não propriamente de uma ação argumentativa. Consiste em produzir uma disposição simpática no entrevistador, usando-se, para tanto, recursos verbais, mas também sorrisos e gestos. Trata-se de tudo o que puder ser feito para capturar simpatia e conquistar boa vontade; ou, ao menos, para diminuir a má vontade. Serra foi relativamente bem sucedido na entrevista do $1^{\circ}$ turno ao Jornal Nacional, ao evitar todo comportamento argumentativo belicoso em face dos jornalistas e adotar uma atitude de aparente docilidade e submissão.

Escapada. Os comportamentos de fuga são frequentemente uma alternativa empreendida pelos entrevistados, principalmente em face de premissas com grande potencial de constrangimento diante das quais as chances de êxito nas respostas são mínimas. Escapadas podem produzir comportamentos de perseguição e acossamento por parte dos jornalistas, e consequente escalada na hostilidade, mas podem se justificar em situação em que alternativas não se apresentam e quando uma resposta direta à questão só poderia provocar ainda maiores prejuízos à imagem do candidato. Consiste na tentativa deliberada de não responder a uma questão ou de não confrontar-se com uma premissa ou um dado factual. 
Questionamento explícito das premissas. Além de adotar comportamentos de esquiva e empreender tentativas de escapada, que são opções que assumem as premissas como dadas, uma forma possível de reação a premissas indesejadas é a rediscussão das hipóteses que elas comportam. Os entrevistados podem recusá-las in toto ou parcialmente, podem aduzir elementos factuais para desqualificá-las ou corrigi-las, podem oferecer alternativas de premissas que lhes sejam mais vantajosas. De todo modo, isso pode ser feito à base de uma negociação verbal com o entrevistador ou numa recusa e confronto, com as desvantagens que essa segunda atitude comporta.

\section{Os modelos de perguntas e premissas}

A entrevista eleitoral parece ter se tornado uma espécie de gênero discursivo à parte, à medida que já se espera dos jornalistas um padrão de atitude e um padrão de questões que as materializam. A depender do estilo pessoal dos entrevistadores, haverá diferentes graus de intensidade, mas o básico da atitude é geralmente o mesmo. Mas há também padrões de perguntas por meio dos quais a atitude de suspeita típica do gênero se materializa. Jornalistas não querem ser percebidos como cooperando com os políticos, por isso as suas questões precisam denotar antes competição do que afinamento. Eis porque as suas perguntas tendem a colocar os entrevistados numa posição desconfortável, desvantajosa ou constrangedora. E eis porque raramente uma intervenção vem em socorro do entrevistado ou lhe serve como apoio para a sua autopromoção (a popular "escada").

Nas entrevistas diretas nas eleições de 2010, as perguntas obedeceram a uma tipologia básica, que dividimos em modelos temáticos e modelos argumentativos. Do ponto de vista temático, houve basicamente questões relacionadas a: a) promessas eleitorais para desafiar a sua exequibilidade, mostrar as inaceitáveis consequências que elas comportam e introduzir o argumento cético acerca de por que não foram ainda realizadas; b) fatos e estratégias relacionadas às campanhas, em geral, para dizer que tais estratégias fracassaram ou estão fracassando, ou que são incoerentes, ou para mostrar fatos inapropriados; c) escândalos políticos relacionados aos candidatos, seus partidos e seus aliados; d) dados ruins de desempenho de governos em que o candidato está ou esteve envolvido, usados para eliminar a possibilidade de auto-elogios ou para criticar os governos que o candidato representa ou representou; e) questões relacionadas à compreensão dos problemas sociais e às políticas necessárias para enfrentá-las. Já é tradicional na literatura sobre campanhas eleitorais a convicção de que questões substantivas 
(do último tipo) são as menos exploradas no jornalismo político; verificamos que também nas entrevistas elas raramente aparecem, talvez porque tenham um potencial de hostilidade e ceticismo muito menor do que os outros quatro tipos de perguntas.

\section{Quadro 2-}

\begin{tabular}{l}
\hline Temas \\
Promessas falsas, irrealizáveis ou inconsequentes \\
Táticas eleitorais fracassadas ou incoerentes \\
Escândalos políticos \\
Desempenho ruim de governos \\
Questões substantivas
\end{tabular}

Mais importante do que a classificação temática é o esforço para posicionar o candidato em termos de conforto vs. desconforto, vantagem vs. desvantagem. A lista temática acima já indica que a quase totalidade das questões foram formuladas para tirar o candidato da sua zona de conforto e colocá-lo em posição defensiva ou na condição de ser obrigado a dar explicações. Além das premissas, há que se prestar atenção a modelos de argumentos empregados geralmente pelos jornalistas nas entrevistas eleitorais. $\mathrm{Na}$ amostra estudada, praticamente todas as falas dos apresentadores empregaram os modelos abaixo, com absoluta ênfase nos cinco primeiros.

\section{Quadro 3 -}

Modelos argumentativos
Te pego numa contradição; vou mostrar a sua incoerência.
Se não fez antes, por que fará agora?
Critique o seu patrono.
Como foi possível que alguém ligado a você fizesse algo tão errado?
Dizem que você é errado, você é errado mesmo?
Fale sobre o problema X; exponha a sua política para resolver Y.

Primeiro, há o modelo da exibição da incoerência ou contradição. Em época de bancos de dados informatizados e registros abundantes, é 
um jogo fácil mostrar como alguém disse ou fez algo diferente ou divergente do que agora diz ou faz. O jogo do "te pego numa incoerência" pode incluir declarações anteriores sobre atuais aliados, o destaque de como adversários mortais do passado agora compõem coalizões, a exibição de mudança de posição dos políticos sobre temas, em geral polêmicos. As premissas que sustentam essas questões são duas: a de que é possível julgar o caráter de alguém pelo nível de inconsistência nas suas opiniões e juízos sobre pessoas e coisas; e a premissa de que se o sujeito muda de opinião e de aliados durante uma campanha é por mera conveniência eleitoral - o que nos leva de novo à premissa sobre o caráter.

O segundo e terceiro modelos são usados para candidatos que são (ou foram) titulares de governos ou que são os candidatos do governo. Consistem em fazê-los responder por desempenhos ruins e malfeitos de gestões passadas. Quando usado para questões sobre promessas eleitorais, este modelo produz a pergunta típica: se não fez em $X$ anos, porque devemos acreditar que fará nos próximos quatro? É usado basicamente para atacar a credibilidade do entrevistado, levantando a suspeita cética de que formula apenas convenientes promessas eleitorais e nada mais. Outra forma comum é jogar o candidato apoiado contra o governo que o apoia, levando-o a criticar comportamentos, políticas ou declarações da administração anterior. A premissa por trás de tudo consiste em afirmar que se alguém faz parte de um governo incompetente ou é apoiado por um governante que diz coisas erradas deve comungar com esses erros e incompetências ou deve, de alguma forma, expiá-los. O objeto claro é apresentar ao candidato o que houver em vermelho na conta do governo anterior.

O quarto modelo consiste em associar a candidatura a escândalos havidos em suas gestões passadas ou de seu partido e associados. As perguntas podem parecer inocentes - "A Senhora não acha que a Casa Civil deveria ter feito alguma coisa para evitar o escândalo Erenice?" - mas o objetivo é, no jargão, colocar no colo do candidato o inconveniente de uma conduta inapropriada, em geral de natureza política, mas não de raro de natureza criminal, sexual etc. Trata-se do mesmo objetivo anterior: uma conta está no vermelho, alguém tem que pagar por ela e tem que ser o candidato que, de algum modo, possa ser associado ao escândalo.

O quinto modelo consiste em exibir dimensões consideradas fracas do candidato, os seus handicaps. O Jornal Nacional gastou $1 / 3$ do tempo da entrevista com Dilma Rousseff no $1^{\circ}$ turno no encalço de uma questão sobre o temperamento ríspido da candidata na lida com os seus colaboradores. Com José Serra, insistiram que ele era autoritário e centralizador. Qualquer dimensão serve: inexperiência administrativa, destempero verbal, erros do passado. Convenientemente, os entrevistadores não ousam formular ao vivo 
um handicap do candidato entrevistado assumindo-se como fonte dos predicados; lançam mão daqueles disponíveis no discurso público, no jornalismo, na voz dos adversários - "Candidato, as pessoas no meio político dizem que...". O máximo de "contribuição" feita explicitamente pelos entrevistadores consiste em explicar por que aquele aspecto é um defeito, que é também quando se explicita a premissa: uma pessoa com tal (falta de) qualidade tem uma falha importante no que se requer para o exercício do cargo.

O sexto modelo, raramente usado, é aquele de questões substantivas sobre o que pensa o candidato sobre os problemas sociais e as políticas públicas que ele prevê para resolvê-las.

\section{0 padrão de perguntas-respostas}

Há um padrão de perguntas e respostas nas entrevistas aos candidatos presidenciais que se mantém constante em quase todas as entrevistas. Uma questão (definida aqui como "um tópico ou tema sobre o qual se indaga o entrevistado") tem como ponto de partida invariavelmente uma premissa, uma tese, em geral não explicitada, porém muito evidente, sobre o tema em tela. Além da premissa, a questão envolve uma pergunta (definida aqui simplesmente como uma "sentença interrogativa") específica, na qual culmina. A questão do aborto na campanha, por exemplo, em princípio poderia supor várias premissas (p. ex., que é ótimo que o aborto, enfim, seja discutido numa campanha; que o aborto é um fenômeno social terrível; que um candidato não deveria ficar mudando de posição sobre o tema do aborto durante a campanha; que o tema do aborto, abordado de forma conservadora e religiosa, não deveria estar presente numa campanha progressista) e se materializar em várias perguntas. A pergunta, por exemplo, o Sr. não acha um retrocesso trazer o tema do aborto para a campanha?, dirigida a José Serra, supõe apenas uma das premissas acima e coloca o entrevistado forçosamente numa posição defensiva.

A primeira fala dos jornalistas é quase invariavelmente a questão fundamental (premissa ou dado + pergunta). Ela inclui, portanto, uma premissa ou hipótese e, frequentemente, admite e veta percursos de resposta. O candidato terá que gastar o seu primeiro lance discursivo para aceitar, elaborar, recusar ou tentar evitar a premissa. Se o candidato aceitar a premissa do entrevistador e oferecer uma resposta aceitável dentro do frame proposto, a questão se esgota no padrão 1/1 (1 pergunta, 1 resposta). Na verdade, na nossa amostra, apenas $11,5 \%$ das questões foram contidas no ritmo pergunta-resposta $1 / 1$. 
Em geral, como a atitude do jornalista é predominantemente crítica, cética e hostil, seria desvantajoso para o candidato aceitar a premissa proposta e ele vai ter que tomar alguma das atitudes possíveis para evitá-la ou recusá-la (esquiva, refutação da premissa etc.). Nesse caso, haverá a segunda fala do jornalista sobre a mesma questão, que serve para corrigir o percurso empreendido pelo candidato na respostas e/ou para reforçar a premissa com outro dado quando o candidato a nega (reiteração ou reforço). o candidato pode, então, dobrar-se à premissa e responder a questão, chegar a uma situação de compromisso, ou continuar resistindo. $30 \%$ das interações seguiram o padrão $2 / 2$, que se revelou o dominante nas entrevistas diretas.

Em caso de resistência continuada - o candidato insiste em não confrontar-se com o perguntado (esquiva), recusa-se a aceitar a hipótese da premissa, diverge da hipótese ou do dado da premissa (refutação da premissa) ou decide falar de outra coisa (escapada) haverá uma terceira fala do jornalista. $16 \%$ das interações, número consideravelmente alto, seguiram o padrão $3 / 3$.

Haver uma quarta e quinta falas dos jornalistas sobre a mesma questão praticamente caracteriza um bate-boca, uma intervenção de autoridade e de hostilidade, em geral para correção e/ou interrupção da argumentação do candidato. Isso, contudo, não é raro, pois $18 \%$ das interações seguiram o padrão $4 / 4$ ou $5 / 5$, que indica que ali houve tentativa de escapada ou insistente tentativa de refutação de premissas por parte do político e as correspondentes atitudes verbais dos entrevistadores.

Os restantes $26 \%$ das interações seguiram em nossa amostra padrões de pergunta-resposta ainda mais longos, entre seis e 11 falas cada. 0 padrão $3 / 3$ e subsequentes configuram aquilo que pode ser chamado de comportamento argumentativo de resistência e fuga, por parte dos candidatos, e de perseguição e cerco por parte do jornalista, que se dá quando os entrevistados continuam resistindo às premissas propostas pelo jornalista, recusando as suas falas de reforços, as suas intervenções corretivas e as suas reiterações. O que produz nos âncoras mais atitudes de reforço e contraposição, podendo chegar a níveis de hostilidades e confrontos que marcam profundamente todo o resto da entrevista e o efeito geral que esta exerce sobre o público.

O padrão de intensidade das interações funciona muito bem para a previsão estatística dos níveis de tensão entre entrevistadores e entrevistados, da cooperação ou competição havida, da aceitação de ou resistência a, por parte dos candidatos, premissas e frames adotados pelos jornalistas. Uma entrevista com um número muito alto de falas por tema é sempre um sinal de que houve tensão entre o 
jornalismo e a política. E, vice-versa, um número muito baixo de falas e falas mais longas sugere um padrão com menor hostilidade.

Tratou-se, neste artigo, basicamente de uma sustentação teórica da tese de que as entrevistas eleitorais diretas das bancadas de telejornais são antes uma arena de competição entre jornalismo e política do que uma mera forma de apresentação da política na televisão. Acontece nas entrevistas não editadas algo muito semelhante ao que se dá com a matéria padrão da cobertura jornalística da política, a saber, a voz política é tratada para que não escape ao controle da instituição jornalística. Ademais, na ausência de instrumentos e recursos de edição, o jornalismo desenvolveu recursos da ordem do discurso para assegurar o seu controle argumentativo da fala política durante as entrevistas eleitorais diretas. Por fim, formulei alguns indicadores que, de forma análoga àqueles elaborados por Hallin para constatar a mudança estrutural do noticiário político nos telejornais, devem ser testados como meios de aferição da competição argumentativa nas entrevistas políticas televisivas. 


\section{Referências}

BARNHURST, K. G.; STEELE, C. A. Image-Bite News: The Visual Coverage of Elections on U.S. Television, 1968-1992. The Harvard International Journal of Press/Politics, v. 2, n. 1, p. 40-58, 1 dez 1996.

BARNHURST, K.; MUTZ, D. American journalism and the decline in event-centered reporting. Journal of Communication, v. 47, n. 4, p. 27-53, dez 1997.

BOWEN, L.; STAMM, K.; CLARK, F. Television Reliance and Political Malaise: A Contingency Analysis. Journal of Broadcasting \& Electronic Media, v. 44, n. 1, p. $1-15$, mar 2000.

BUCY, E. P.; GRABE, M. E. Taking Television Seriously: A Sound and Image Bite Analysis of Presidential Campaign Coverage, 1992-2004. Journal of Communication, v. 57, n. 4, p. 652-675, $12 \mathrm{dez} 2007$.

EKSTRÖM, M. Politicians Interviewed on Television News. Discourse \& Society, v. 12, n. 5, p. 563-584, 1 set 2001.

EKSTRÖM, M. Gaze work in political media interviews. Discourse \& Communication, v. 6, n. 3, p. 249-271, 16 ago 2012.

ESSER, F. Dimensions of Political News Cultures: Sound Bite and Image Bite News in France, Germany, Great Britain, and the United States. The International Journal of Press/Politics, v. 13, n. 4, p. 401-428, 13 jun 2008.

GINER-SOROLA, R.; CHAIKEN, S. The causes of hostile media judgments. Journal of Experimental Social Psychology, v. 30, p. 165-180, 1994.

GOMES, W. Audioesfera política brasileira e visibilidade pública. In: GOMES, Itania (org.). Televisão e realidade. Edufba: Salvador, 2009.

GRACE, E. G.; BUCY, E. P. Image bite politics: News and the visual framing of elections. Oxford University Press: New York, 2009.

GUNTHER, A. C. Biased Press or Biased Public? Attitudes Toward Media Coverage of Social Groups. Public Opinion Quarterly, v. 56, n. 2, p. 147, jan 1992.

HALLIN, D. Soundbite news: Television coverage of elections, 1968-88. In: HALLIN, D. C. We keep America on top of the world. Routledge, London, 1994.

HUGE, M.; GLYNN, C. J. Hostile Media and the Campaign Trail: Perceived Media Bias in the Race for Governor. Journal of Communication, v. 60, n. 1, p. 165-181, mar 2010.

MEYER, H. K.; MARCHIONNI, D.; THORSON, E. The Journalist Behind the News: Credibility of Straight, Collaborative, Opinionated, and Blogged "News". American Behavioral Scientist, v. 54, n. 2, p. 100-119, 28 set 2010.

NORRIS, P. Social Capital and the News Media. The Harvard International Journal of Press/Politics, v. 7, n. 1, p. 3-8, 1 jan 2002.

RICHARDSON, J. D.; HUDDY, W. P.; MORGAN, S. M. The Hostile Media Effect, Biased Assimilation, and Perceptions of a Presidential Debate. Journal of Applied Social Psychology, v. 38, n. 5, p. 1255-1270, maio 2008. 
VALLONE, R. P.; ROSS, L.; LEPPER, M. R. The hostile media phenomenon: Biased perception and perceptions of media bias in coverage of the Beirut massacre. Journal of Personality and Social Psychology, v. 49, n. 3, p. 577-85, set 1985.

WEST, Darrell, KERN, Montague, ALGER, Dean, GOGGIN, Janice. Ad Buys in Presidential Campaingns: The Strategies of electoral Appeal. Political Communication, vol. 12, 1995, p. 275-290.

A Revista Compolítica é uma revista eletrônica da Associação Brasileira de

Pesquisadores em Comunicação e Política. Com periodicidade semestral, sua proposta é difundir a produção acadêmica relacionada às interfaces desses campos de estudo. 